\title{
Application of iNKT Cell-targeted Active Immunotherapy in Cancer Treatment
}

\author{
KIMIHIRO YAMASHITA ${ }^{1}$, AKIRA ARIMOTO ${ }^{1}$, MASAYASU NISHI ${ }^{1}$, TOMOKO TANAKA $^{1}$, \\ MITSUGU FUJITA $^{2}$, EIJI FUKUOKA ${ }^{1}$, YUTAKA SUGITA ${ }^{1}$, AKIO NAKAGAWA ${ }^{1}$, \\ HIROSHI HASEGAWA ${ }^{1}$, SATOSHI SUZUKI ${ }^{1}$ and YOSHIHIRO KAKEJI ${ }^{1}$ \\ ${ }^{1}$ Department of Surgery, Division of Gastrointestinal Surgery, \\ Kobe University Graduate School of Medicine, Kobe, Japan; \\ ${ }^{2}$ Department of Microbiology, Kindai University Faculty of Medicine, Osaka, Japan
}

\begin{abstract}
In tumor immunity, invariant natural killer $T$ (iNKT) cells play a pivotal role as a link between the innate and adaptive immune systems. With a precisely regulated activation mechanism, iNKT cells have the ability to respond quickly to antigenic stimulation and rapidly produce cytokines and chemokines, and subsequently an effective antitumor immune response. The development of iNKT cell-targeted active immunotherapy enables, not only an antitumor immune response through innate and acquired immunity, but also the conversion of an immunosuppressive into an immunogenic microenvironment. This review is focused on the activation mechanism and the role of $i N K T$ cells after therapeutic active immunization. The therapeutic strategy targeting iNKT cells is expected to be applied to clinical practice in combination with surgery and chemotherapy.
\end{abstract}

The clinical development of checkpoint inhibitor-based immunotherapy has introduced a new era in cancer treatment $(1,2)$. Durable responses, characteristic of acquired immunity, can be seen clinically in patients with several types of cancers, including melanoma $(3,4)$. The emergence of strong, evidencebased therapy has enabled immunological therapeutic interventions in a clinical setting, which then has highlighted

This article is freely accessible online.

Correspondence to: Kimihiro Yamashita, MD, Ph.D., Department of Surgery, Division of Gastrointestinal Surgery, Kobe University Graduate School of Medicine, 7-5-2 Kusunoki-cho, Chuo-ku, Kobe, Hyogo 650-0017, Japan. Tel: +81 783825925, Fax: +81 783825939, e-mail: kiyama@med.kobe-u.ac.jp

Key Words: iNKT cells, $\alpha$-galactosylceramide, immunogenic cell death, review. a need to demonstrate the effects of combinations with other types of therapy, including conventional and immunotherapy, as well as treatment that is still being developed.

Natural killer T (NKT) cell-based immunotherapy is one of the most promising types of immunotherapy currently in development. In tumor immunity, the immune systems participate in immune surveillance against tumor development and respond to the foreignness of tumor cells. The innate immune cell population recognizes tumor-associated antigens and danger signals from tumor cells and responds quickly to them. Effector cells typified by natural killer (NK) cells start to eliminate tumor cells directly. In addition, antigenpresenting cells such as dendritic cells (DCs) and macrophages take up the antigens, and are responsible for induction and enhancement of the acquired immunity, followed by the subsequent formation of antigen-specific $\mathrm{B}$ and $\mathrm{T}$ cells (5). One of the key players that link the innate and the adaptive immune systems is the NKT cells. They have the ability to respond quickly to antigenic stimulation and rapidly produce cytokines (6). Mediated by these cytokines, crosstalk between applicable immune cells activates the whole immune system and enables an effective antitumor immune response $(7,8)$. Invariant natural killer T (iNKT) cells comprise an innate-like subset of $\mathrm{T}$ lymphocytes that carry a distinctive invariant $\mathrm{T}$ cell receptor (TCR) $\alpha$ chain paired with a limited repertoire of TCR $\beta$-chains; these cells recognize a variety of lipid antigens when bound to a major histocompatibility (MHC) class I-like molecule, CD1d (9). Many researchers have explored the possibility of cancer immunotherapy using iNKT cells, that is an attractive tool to activate both innate and adaptive immunity. Although novel treatments including induced pluripotent stem (iPS) cells, chimeric antigen receptors, biphasic antibodies, and nanotechnology are being developed one after another $(10,11)$, this review focuses on iNKT cell-targeted active immunotherapy. 


\section{Activation of iNKT Cells}

After activation, NKT cells can secrete large amounts of various types of cytokines and exhibit both proinflammatory and immunoregulatory characteristics. Depending on their T cell receptor (TCR), CD1d-restricted NKT cells are subdivided into type I or invariant NKT (iNKT) cells, and type II NKT cells. Type I NKT cells have an invariant TCR $\alpha$ chain, whereas type II cells have more diverse alpha-beta TCRs. The TCR of Type I NKT cells is composed of a single $\alpha$ chain ( $\mathrm{V} \alpha 14 \mathrm{~J} \alpha 18$ in mice and $\mathrm{V} \alpha 24 \mathrm{~J} \alpha 18$ in humans) paired with limited diverse $\beta$ chains (V $\beta 8.2,7$ or 2 in mice and V $\beta 11$ in humans) (9). Type II NKT cell is a subset involved in immunosuppression in tumor-bearing hosts or in autoimmune disease (12). This report discusses iNKT cells.

iNKT cells receive signals through various types of receptors. The TCRs of iNKT cells recognize lipid antigens that comprise endogenous self-lipids and exogenous nonpeptide lipids, mainly microbe-derived presented through molecular interaction with the CD1d molecule (13). CD1d is a non-polymorphic MHC class I-like molecule constitutively expressed on antigen-presenting cells such as DCs, B cells, and macrophages. The well-studied agonist for iNKT cells is $\alpha$-galactosylceramide ( $\alpha$-GalCer or KRN 7000), which is isolated from a marine sponge (14).

Upon antigenic stimulation, iNKT cells respond within a few hours by producing large amounts of Th1, Th2, and Th17 cytokines (15). This rapid response can be attributed to their storage of cytokine mRNA in the cytoplasm before activation (16). Interestingly, iNKT cells have phenotypically activated and memory-like properties (17). In addition, the multifunctionality of cytokine production is due to the capacity of iNKT cells to differentiate into mature effector subsets that produce IFN- $\gamma$, IL-4, or IL-17 in the thymus. These subsets are designated as NKT1, NKT2, and NKT17 cells, respectively, and their lineage properties are determined by key transcriptional factors including promyelocytic leukemia zinc finger (PLZF), T-cell-specific T-box transcription factor (T-bet) in Th1 lineage, GATA binding protein 3 to DNA sequence (GATA-3) in Th2 lineage, and retinoic acid-related orphan receptor $\gamma \mathrm{t}$ (ROR $\gamma \mathrm{t})$ in Th17 lineage, similar to the differentiation of conventional T cells $(18,19)$.

An important point in iNKT cell research is the method of administration of foreign antigens (Figure 1), which is termed active immunotherapy. Active immunotherapy is a therapeutic intervention that causes activation of the immune system in vivo by exogenous stimulation. After $\alpha$-GalCer was identified as a specific ligand for iNKT cells, the effects of administration of free $\alpha$-GalCer have been studied enthusiastically. A drawback of administering free $\alpha$-GalCer is that it causes iNKT cells to adopt an anergic state, causing unresponsiveness to sequential stimulation with $\alpha$-GalCer
(13). Fujii and colleagues demonstrated prolonged IFN- $\gamma$ production and antitumor effect after intravenous administration of bone marrow-derived DCs loaded with $\alpha$ GalCer (DCs/Gal), that express a high level of CD1d (20).

In addition, from a clinical point of view, it should be noted that administration of $\alpha$-GalCer may cause liver injury that often results in lethality (21). We showed that this adverse effect is due to antigen presentation by intrahepatic vascular endothelial cells and that it is rarely lethal in DCs/Gal administration (22).

\section{The Role of iNKT Cells in Targeted Active Immunotherapy}

In the antitumor immune response following active immunotherapy, the mechanism of action of iNKT cells are as follows: (a) direct tumor killing, (b) induction and activation of NK cells, (c) induction of cytotoxic T lymphocytes (CTLs), (d) modulation of immunosuppressive tumor microenvironment (Figure 2). This type of immunotherapy activates iNKT cells and enables NK cells to eliminate MHC-negative tumors, and antigen-specific CD8 cytotoxic T cells to kill MHC-positive tumors.

Direct tumor killing activity of iNKT cells. The direct killing ability of iNKT cells has been analyzed against tumors expressing CD1d in vitro. The function is exerted through the perforin/granzyme B (23), Fas - Fas ligand system (24), and tumor necrosis factor- $\alpha$-related apoptosis-inducing ligand (TRAIL) (25). These studies revealed that tumors expressing CD1d may be the targets of iNKT cells. But declining expression of CD1d on tumor cells does not necessarily reflect disease progression (26).

Induction of NK cells by iNKT cell activation. With regard to the response of NK cells, the activated iNKT cells secrete IL-2 and IFN- $\gamma$, and directly activate NK cells (27). In addition, after activation, iNKT cells express CD40L and promote maturation of DCs through a CD40-CD40L signal. DCs produce IL-12 and expresses NKG 2 D ligands and CD 70 (CD 27 ligand) $(28,29)$. Each of these signals can further enhance the response of NK cells and are essential for NK cells to exhibit sufficient antitumor effect (30); we clarified that this is important in a mouse B16 melanoma lung metastasis model (31).

Clinically, in cancer patients, it is difficult to secure adequate amounts of DCs. To solve this problem, we showed that allogenic bone-marrow-derived DCs /Gal that meet the above conditions, produce a guaranteed therapeutic effect (32).

Efficient induction of CTLs against tumor. The induction of CTLs is accompanied by maturation of DCs. In the tumor tissue, most of DCs are immature. But maturation of DCs is essential to induce a sufficient CTL-mediated reaction. DCs 


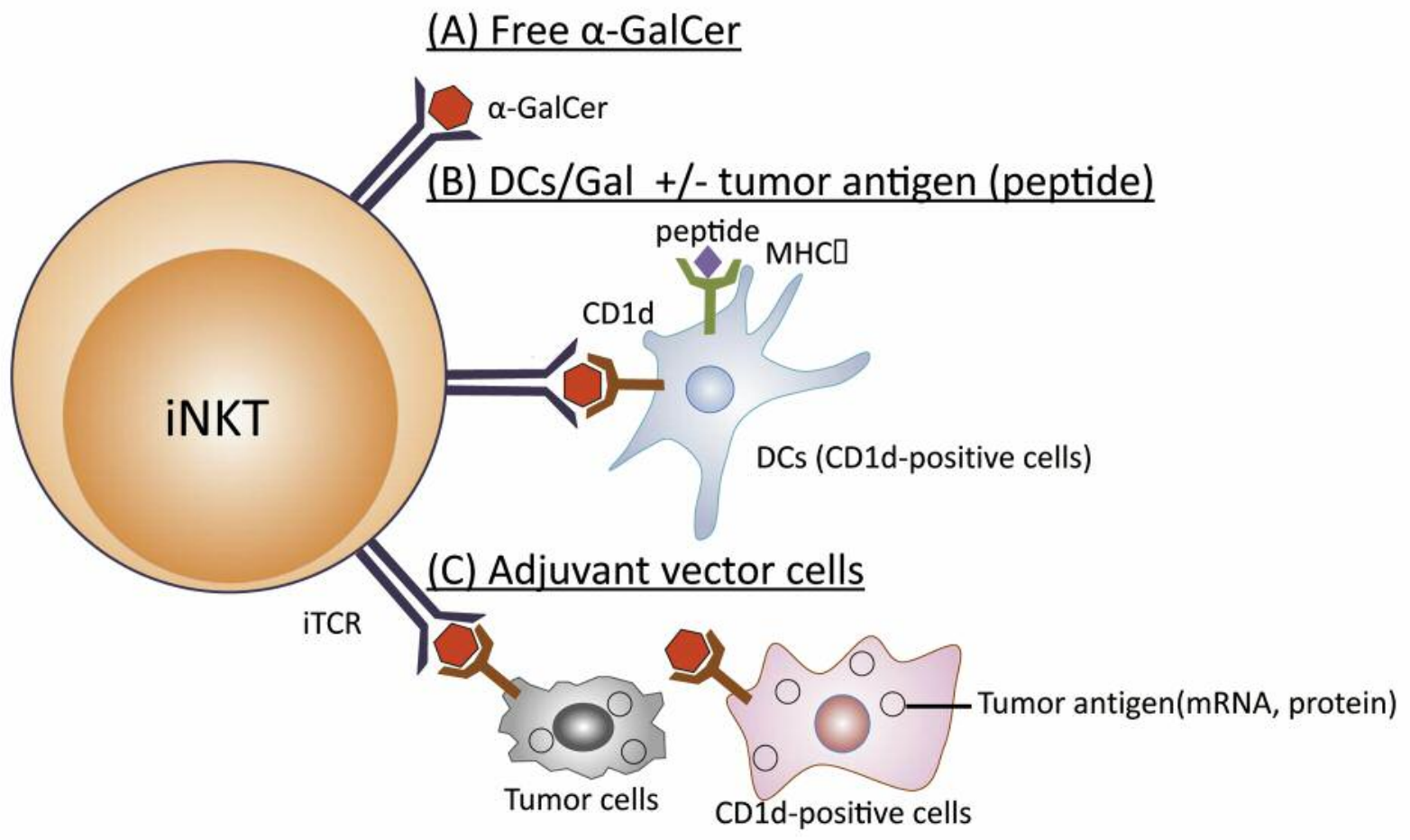

Figure 1. Invariant natural killer T (iNKT) cell activation by active immunization. A: Administration of free $\alpha$-galactosylceramide ( $\alpha$-GalCer). The problem of administration of free $\alpha$-GalCer is to bring about an anergic state and lethality. B: Administration of dendritic cells (DCs) loaded with $\alpha$-GalCer (DCs/Gal) with or without tumor antigen. Administration of DCs/Gal has less capacity to induce antigen-specific CD8 T cells.C: Administration of adjuvant vector cells, including tumor cells loaded with $\alpha$-GalCer or tumor antigen mRNA-transfected, allogeneic CD1d-positive cells loaded with $\alpha$-GalCer. TCR: T cell receptor; MHC I: major histocompatibility I; iTCR: invariant TCR; mRNA: messenger ribonucleic acid.

and iNKT cells interact with CD1d/antigen complexes. Ligation of APC-expressed CD40 with up-regulated CD40L on iNKT cells induces maturation of DCs that express costimulation molecules on the cell surface and gain the capacity of IL-12 production. IL-12 secreted by mature DCs induces IFN- $\gamma$ production by NKT cells (33). IFN- $\gamma$ secreted by iNKT cells and NK cells promotes maturation of DCs, but expression of co-stimulatory molecules, such as CD40, CD80, CD86, on DCs are important for the CTL priming $(34,35)$. Moreover, iNKT cells and fully activated DCs produce CCL17, which attracts CCR4-positive CD8 T cells, for CTL priming (36).

Utilization of iNKT cells in cancer vaccine treatment. Coadministration intravenously of tumor antigen with $\alpha$-GalCer brings about rapid DC maturation and induction of an effective adaptive immune response to tumors $(34,35)$. Several optimal conditions are necessary for successful treatment. The context is that immature DCs phagocytose tumor antigens and, after adequate maturation by iNKT cells, they present tumor antigens to antigen-specific CTLs. Therefore, it is a necessary condition that activated iNKT cells are presented with tumor antigen and endogenous immature DCs simultaneously. The administration of cells expressed high level of CD1d such as B cells or myeloid-derived suppressor cells (MDSCs) and, loaded with $\alpha$-GalCer and peptide of tumor antigen, can induce CTL responses $(37,38)$, but cannot generate memory formation easily. Fujii and colleagues indicated the essential conditions to generate a memory response as follows: (1) the numbers and functions of iNKT cells and APCs, (2) the ligands, (3) the properties of host APCs, and (4) the level of CD1d expression (39). Under these conditions, the magnitude of the innate immune response can shape the subsequent immune response with adequate antitumor effect. At present, the most effective cell option for adjuvant vectors is antigen mRNA-transfected fibroblasts, called artificial adjuvant vector cells (aAVC) (40). More recently, a new NKT cell glycolipid ligand with strong adjuvant effect called RK have been identified. RK-loaded DCs induced strong antitumor effect and long-lasting memory reaction (41). The development of these therapies, not only dramatically pushed research to preclinical models, but also strongly indicated that this approach may eventually provide a clinically promising treatment. 


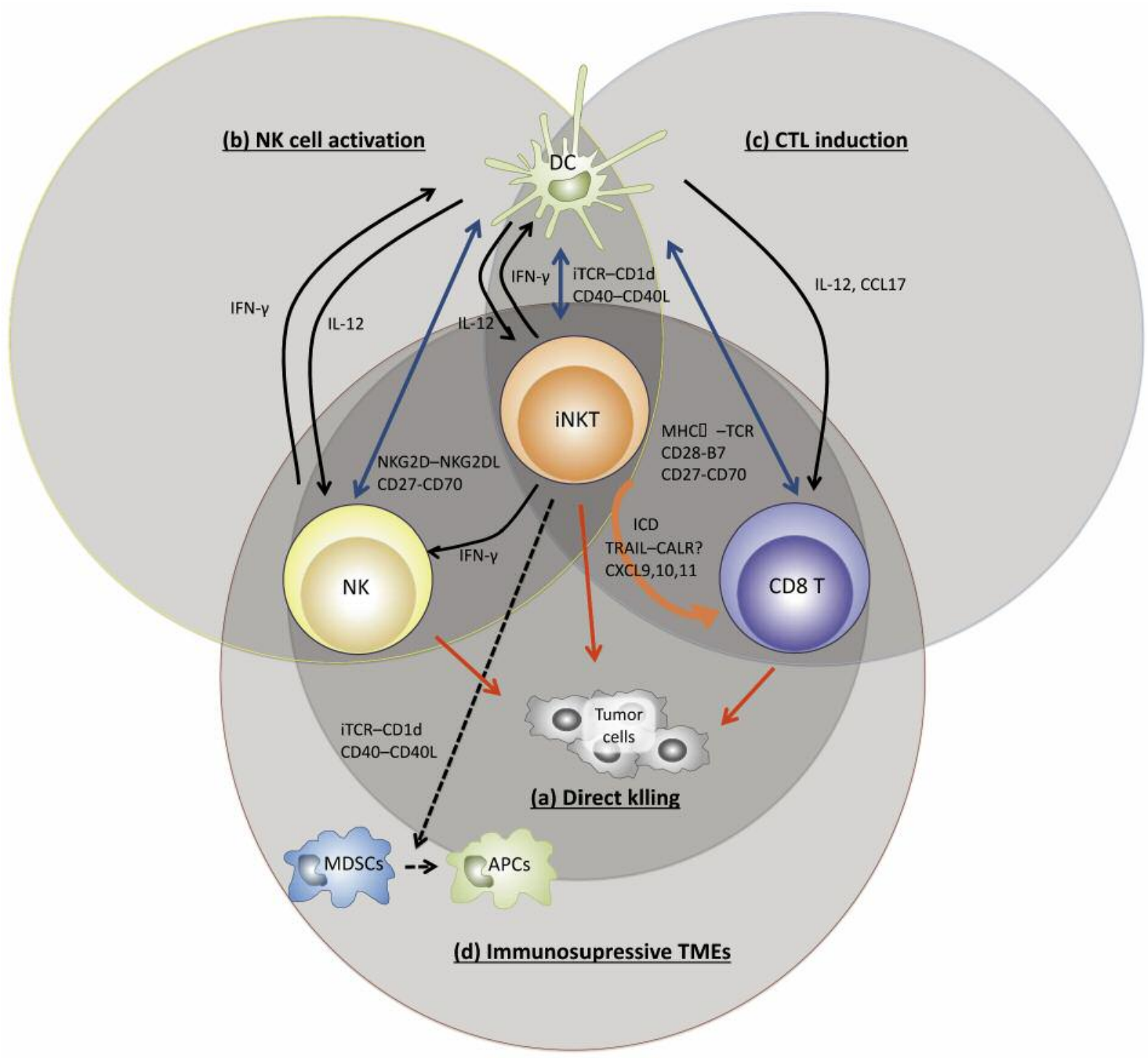

Figure 2. The role of invariant natural killer T (iNKT) cells in antitumor responses in tumor microenvironments (TMEs). A: Direct tumor killing. iNKT cells exert direct cytotoxicity to tumor cells. B: Induction and activation of natural killer (NK) cells. Activated iNKT cells directly activate $N K$ cells via interleukin (IL)-2, interferon (IFN)- $\gamma$, and indirectly via IL-12 secreted by dendritic cells (DCs) and natural killer group 2 member D (NKG 2 D) ligands and CD 70 (CD 27 ligand) expressed on dendritic cells. C: Induction of CTL priming and generation of memory response. The vector cells are killed by iNKT cells and NK cells, and then tumor antigen can be captured by endogenous DCs. The DCs promote iNKT cell-induced maturation. The activated DCs can then induce an antigen-specific T cell response. D: Modulation of immunosuppressive TMEs. iNKT cells covert immunosuppressive to immunogenic microenvironments by Th1 cytokines production, maturation of myeloid-derived suppressor cells (MDSCs) to antigen-presenting cells (APCS), and induction of immunogenic cell death (ICD) of tumor. TCR: T cell receptor; MHC I: major histocompatibility I; iTCR: invariant TCR; CXC17: chemokine ligand 17; CXCR4: chemokine receptor 4.

Modulation of immunosuppressive tumor microenvironment. MDSCs play a crucial role to establishing an immunosuppressive tumor microenvironment (42). The ability of iNKT cells to convert an immunosuppressive to an immunogenic microenvironment is based on their capacity to promote the maturation of MDSCs into mature myeloid cells, which results in resolution of MDSC-mediated immunosuppression $(37,43)$.
Next, the ability to convert the tumor microenvironment of iNKT cell-targeted therapy in a poor immunogenic tumor will be described. Many researchers are convinced that induction of $\mathrm{T}$ cells is the key to increase the success of checkpoint inhibitors against tumors. The immunogenic cell death (ICD) refers to a unique tumor cell death mediated through activation of innate immune cells and facilitation of 
the acquired immune response of antigen-specific $\mathrm{T}$ cell towards dead cell-derived antigens (44). When tumor cells die by necrosis, they expose on the cell surface or secrete molecules called danger-associated molecular patterns (DAMPs). The DAMPs are molecules that are present in tumor cells and released outside the cell at the time of cell death, but they function as immunostimulatory molecules and trigger ICD to convert the tumor microenvironment from a T-cell poor to a T-cell rich. DAMPs intimately associated to NKT cells, are high mobility group box1 (HMGB1), adenosine triphosphate(ATP), and calreticulin(CALR). Presumably, HMGB1 binds to TLR4 on the surface of CD1d-positive cells, which results in activation of iNKT cells (45). However, a series of cellular vaccine therapies are considered TLR-independent (34).

ATP regulates immunomodulatory receptors on immune cells and enhances the strength of the TCR signal even with weak stimulation (46).

In addition, CALR normally resides in the lumen of the endoplasmic reticulum (ER), from where it translocates to the surface of apoptotic tumor cells on induction of ICD. The tumor cells can then be recognized and taken up by DCs. As mentioned above, iNKT cells up-regulate TRAIL that directly kills target cells. Interestingly, TRAIL signaling induces CALR on tumor cells. CALR directly interacts with TRAIL and its receptor-signaling complex, as well as with other TNF family members. While further studies are required on how the CALR-TRAIL interaction is related to the antitumor effect mediated by iNKT cells, this interaction is expected to be the key to elucidate the mechanism of iNKT cell-mediated immunotherapy in various cancers (47). iNKT cell-targeted active immunotherapies cause ICD. In fact, aAVC against melanoma increased the concentrations of CXCL9, 10, and 11 in the tumor sites and in DCs, and eventually induced antigen-specific $\mathrm{T}$ cells into the tumor (48). Especially, CXCL10 is one of DAMPs components, that stimulate and recruit activated T cells (49). Furthermore, CD70, 4-1-BBL, and IL-15R $\alpha$ on DCs are essential for generating memory in antigen-specific CTLs.

Combination therapy with surgery or chemotherapy. In many solid cancer types, surgery is the best-choice treatment for localized disease with the objective of achieving complete resection of the tumors. However, once a postoperative recurrence occurs, it is directly related to death. In the relapse model after resection of the primary tumor in a triplenegative breast tumor, treatment with $\alpha$-GalCer-loaded DCs limited tumor metastasis, prolonged survival, and provided curative outcomes (50). We elucidated that the frequency of MDSCs of the peripheral blood can be a recurrence marker in a B16 melanoma model (51). The aim of this treatment is to regulate the number of MDSCs and show its effect by inducing antigen-specific reactions. In a similar model, the effectiveness of combination of $\alpha$-GalCer-loaded DCs with gemcitabine or cyclophosphamide, that is a chemotherapy that causes ICD, has also been proposed (52).

\section{Conclusion}

Currently, based on preclinical models, iNKT cell-based immunotherapies are expected to increase the rate of complete response after resection of tumor or to maintain a state of long-term stable disease. In order to realize this therapeutic success, the generation of effective CTL memory cells is necessary by inducing ICD and establishing an effective innate immune response. For this purpose, further analysis of iNKT cell-targeted immunotherapy should focus on development of effective specific ligands and elucidation of their detailed interaction with tumor antigens.

\section{Conflicts of Interest}

The Authors have no conflict of interest in regard to this study.

\section{Acknowledgements}

This work was supported by a Grant-in-Aid from the Ministry of Education, Culture, Sports, Science, and Technology of Japan (KY: No. 16K10541).

\section{References}

1 Pardoll DM: The blockade of immune Slide checkpoints in cancer immunotherapy. Nat Rev Cancer 12: 252-264, 2012.

2 Sharma P, Hu-Lieskovan S, Wargo JA and Ribas A: Primary, adaptive and acquired resistance to cancer immunotherapy. Cell 168: 707-723, 2017.

3 Schadendorf D, Hodi FS, Robert C, Weber JS, Margolin K, Hamid O, Patt D, Chen TT, Berman DM and Wolchok JD: Pooled analysis of long-term survival data from phase II and phase III trials of ipilimumab in unresectable or metastatic melanoma. J Clin Oncol 33: 1889-1894, 2015.

4 Gettinger S, Horn L, Jackman D, Spigel D, Antonia S, Hellmann M, Powderly J, Heist R, Sequist L, Smith DC, Leming P, Geese WJ, Yoon D, Li A and Brahmer J: Five-year follow-up from the CA209-003 study of nivolumab in previously treated advanced non-small cell lung cancer: Clinical characteristics of long-term survivors. Thorac Oncol, 2018. doi: 10.1200/JCO.2017.77.0412. [Epub ahead of print]

5 Gajewski TF, Schreiber $\mathrm{H}$ and Fu YX: Innate and adaptive immune cells in the tumor microenvironment. Nat Immunol 14: 1014-1022, 2013.

6 Coquet JM, Chakravarti S, Kyparissoudis K, McNab FW, Pitt LA, McKenzie BS, Berzins SP, Smyth MJ and Godfrey DI: Diverse cytokine production by NKT cell subsets and identification of an IL-17-producing CD4-NK1.1- NKT cell population. Proc Natl Acad Sci 105: 11287-11292, 2008.

7 Kim EY, Lynch L, Brennan PJ, Cohen NR and Brenner MB: The transcriptional programs of iNKT cells. Semin Immunol 27: 26$32,2015$. 
8 Godfrey DI, Pellicci DG, Patel O, Kjer-Nielsen L, McCluskey J and Rossjohn J: Antigen recognition by CD1d-restricted NKT T cell receptors. Semin Immunol 22: 61-67, 2010.

9 Macho-Fernandez E and Brigl M: The extended family of CD1d-restricted NKT cells: Sifting through a mixed bag of TCRs, antigens, and functions. Front Immunol 6: 362, 2015.

10 Felley L and Gumperz JE: Are human iNKT cells keeping tabs on lipidome perturbations triggered by oxidative stress in the blood? Immunogenetics 68: 611-622, 2016.

11 Zhu H, Lai YS, Li Y, Blum RH and Kaufman DS: Concise Review: Human pluripotent stem cells toproduce cell-based cancer immunotherapy. Stem Cells 36: 134-145, 2018.

12 Dhodapkar MV and Kumar V: Type II natural killer T (NKT) cells and their emerging role in health and disease. J Immunol 198: 1015-1021, 2017.

13 Van Kaer L, Parekh VV and Wu L: The response of CD1drestricted invariant NKT cells to microbial pathogens and their products. Front Immunol 6: 1-11, 2015.

14 Kawano T, Cui J, Koezuka Y, Toura I, Kaneko Y, Motoki K, Ueno $\mathrm{H}$, Nakagawa R, Sato H, Kondo E, Koseki H and Taniguchi M: CD1d-restricted and TCR-mediated activation of $\mathrm{V}(\alpha) 14$ NKT cells by glycosylceramides. Science 278: 1626-1629, 1997.

15 Monteiro M and Graca L: iNKT Cells: Innate lymphocytes with a diverse response. Crit Rev Immunol 34: 81-90, 2014.

16 Stetson DB, Mohrs M, Reinhardt RL, Baron JL, Wang Z-E, Gapin L, Kronenberg M and Locksley RM: Constitutive cytokine mRNAs mark natural killer (NK) and NK T cells poised for rapid effector function. J Exp Med 198: 1069-1076, 2003.

17 Godfrey DI, Stankovic S and Baxter AG: Raising the NKT cell family. Nat Immunol 11: 197-206, 2010.

18 Seiler MP, Mathew R, Liszewski MK, Spooner C, Barr K, Meng $\mathrm{F}$, Singh $\mathrm{H}$ and Bendelac A: Elevated and sustained Egr1 and Egr2 expression controls NKT lineage differentiation in response to TCR signaling. Nat Immunol 13: 264-271, 2012.

19 Constantinides MG and Bendelac A: Transcriptional regulation of the NKT cell lineage. Curr Opin Immunol 25: 161-167, 2013.

20 Fujii S, Shimizu K, Kronenberg M and Steinman RM: Prolonged IFN- $\gamma$-producing NKT response induced with $\alpha$ galactosylceramide-loaded DCs. Nat Immunol 3: 867-874, 2002.

21 Cao Z, Dhupar R, Cai C, Li P, Billiar TR and Geller DA: A critical role for IFN regulatory factor 1 in NKT cell-mediated liver injury induced by -galactosylceramide. J Immunol 185 : 2536-2543, 2010.

22 Hasegawa H, Yamashita K, Otsubo D and Kakeji Y: Liver injury after invariant NKT cell activation by free alphagalactosylceramide and alpha-galactosylceramide-loaded dendritic cells. Anticancer Res 36: 3667-3672, 2016.

23 Bassiri H, Das R, Guan P, Barrett DM, Brennan PJ, Banerjee PP, Wiener SJ, Orange JS, Brenner MB, Grupp SA and Nichols KE: iNKT cell cytotoxic responses control t-lymphoma growth in vitro and in vivo. Cancer Immunol Res 2: 59-69, 2014.

24 Wingender G, Krebs P, Beutler B and Kronenberg M: Antigenspecific cytotoxicity by invariant NKT cells in vivo is CD95/CD178 dependent and is correlated with antigenic potency. J Immunol 185: 2721-2729, 2001.

25 Nieda M, Nicol A, Koezuka Y, Kikuchi A, Lapteva N, Tanaka Y, Tokunaga K, Suzuki K, Kayagaki N, Yagita H, Hirai H and Juji T: TRAIL expression by activated human CD4(+)V alpha 24 NKT cells induces in vitro and in vivo apoptosis of human acute myeloid leukemia cells. Blood 97: 2067-2074, 2001.
26 Bojarska-Junak A, Hus I, Chocholska S, Tomczak W, Woś J, Czubak P, Putowski L and Roliński J: CD1d expression is higher in chronic lymphocytic leukemia patients with unfavorable prognosis. Leuk Res 38: 435-442, 2014.

27 Hayakawa Y, Takeda K, Yagita H, Kakuta S, Iwakura Y, Van Kaer L, Saiki I and Okumura K: Critical contribution of IFNgamma and NK cells, but not perforin- mediated cytotoxicity, to anti-metastatic effect of alpha-Galactosylceramide. Eur J Immunol 31: 1720-1727, 2001.

28 Zhang J, Basher $\mathrm{F}$ and Wu JD: NKG2D ligands in tumor immunity: Two sides of a coin. Front Immunol 6: 1-7, 2015.

29 Arora P, Baena A, Yu KOA, Saini NK, Kharkwal SS, Goldberg MF, Kunnath-Velayudhan S, Carreño LJ, Venkataswamy MM, Kim J, Lazar-Molnar E, Lauvau G, Chang Y tae, Liu Z, Bittman R, Al-Shamkhani A, Cox LR, Jervis PJ, Veerapen N, Besra GS and Porcelli SA: A single subset of dendritic cells controls the cytokine bias of natural killer $\mathrm{T}$ cell responses to diverse glycolipid antigens. Immunity 40: 105-116, 2014.

30 Fujii S, Liu K, Smith C, Bonito AJ and Steinman RM: The linkage of innate to adaptive immunity via maturing dendritic cells in vivo requires CD40 ligation in addition to antigen presentation and CD80/86 costimulation. J Exp Med 199: 16071618, 2004.

31 Yamashita K, Hasegawa H, Fujita M, Nishi M, Tanaka T, Arimoto A, Suzuki S, Kamigaki T and Kakeji Y: Host CD40 is essential for DCG treatment against metastatic lung cancer. Anticancer Res 36: 3659-3665, 2016.

32 Hasegawa H, Yamashita K, Otubo D, Fujii S, Kamigaki T, Kuroda D and Kakeji Y: Allogeneic DCG promote lung NK cell activation and antitumor effect after invariant NKT cell activation. Anticancer Res 34: 3411-3417, 2014.

33 Kitamura H, Iwakabe K, TakashiYahata, Nishimura S, Ohta A, Ohmi Y, Sato M, Takeda K, Okumura K, Kaer L Van, Kawano T, Taniguchi M and Nishimura T: The Natural Killer T (NKT) cell ligand -galactosylceramide demonstrates its immunopotentiating effect by inducing interleukin (IL)-12 production by dendritic cells and IL-12 receptor expression on NKT cells. J Exp Med 189: 1121-1128, 1999.

34 Fujii S, Shimizu K, Smith C, Bonifaz L and Steinman RM: Activation of natural killer $\mathrm{T}$ cells by $\alpha$-Galactosylceramide rapidly induces the full maturation of dendritic cells in vivo and thereby acts as an adjuvant for combined CD4 and CD8 T cell immunity to a coadministered protein. J Exp Med 198: 267-279, 2003.

35 Hermans IF, Silk JD, Gileadi U, Salio M, Mathew B, Ritter G, Schmidt R, Harris AL, Old L and Cerundolo V: NKT Cells Enhance CD4+ and CD8+ T cell responses to soluble antigen in vivo through direct interaction with dendritic cells. J Immunol 171: 5140-5147, 2003.

36 Semmling V, Lukacs-Kornek V, Thaiss CA, Quast T, Hochheiser K, Panzer U, Rossjohn J, Perlmutter P, Cao J, Godfrey DI, Savage PB, Knolle PA, Kolanus W, Förster I and Kurts C: Alternative cross-priming through CCL17-CCR4-mediated attraction of CTLs toward NKT cell-licensed DCs. Nat Immunol 11: 313-320, 2010.

37 Ko HJ, Lee JM, Kim YJ, Kim YS, Lee KA and Kang CY: Immunosuppressive myeloid-derived suppressor cells can be converted into immunogenic apcs with the help of activated NKT cells: An Alternative cell-based antitumor vaccine. J Immunol 182: 1818-1828, 2009. 
38 Chung Y, Kim BS, Kim YJ, Ko HJ, Ko SY, Kim DH and Kang CY: CD1d-restricted T cells license B cells to generate longlasting cytotoxic antitumor immunity in vivo. Cancer Res 66 : 6843-6850, 2006.

39 Fujii $\mathrm{S}$ ichiro and Shimizu K: Exploiting antitumor immunotherapeutic novel strategies by deciphering the cross talk between invariant NKT cells and dendritic cells. Front Immunol 8: 886, 2017.

40 Fujii SI, Goto A and Shimizu K: Antigen mRNA-transfected, allogeneic fibroblasts loaded with NKT-cell ligand confer antitumor immunity. Blood 113: 4262-4272, 2009.

41 Dashtsoodol N, Shigeura T, Tashiro T, Aihara M, Chikanishi T, Okada H, Hanada K, Sano H, Kurogi A and Taniguchi M: Natural killer T cell-targeted immunotherapy mediating longterm memory responses and strong antitumor activity. Front Immunol 8: 1206, 2017.

42 Gabrilovich DI: Myeloid-derived suppressor cells. Cancer Immunol Res 5: 3-8, 2017.

43 Lee JM, Seo JH, Kim YJ, Kim YS, Ko HJ and Kang CY: The restoration of myeloid-derived suppressor cells as functional antigen-presenting cells by NKT cell help and all-trans-retinoic acid treatment. Int J Cancer 131: 741-751, 2012.

44 Bloy N, Garcia P, Laumont CM, Pitt JM, Sistigu A, Stoll G, Yamazaki T, Bonneil E, Buqué A, Humeau J, Drijfhout JW, Meurice G, Walter S, Fritsche J, Weinschenk T, Rammensee HG, Melief C, Thibault P, Perreault C, Pol J, Zitvogel L, Senovilla L and Kroemer G: Immunogenic stress and death of cancer cells: Contribution of antigenicity vs. adjuvanticity to immunosurveillance. Immunol Rev 280: 165-174, 2017.

45 Bianchi ME, Crippa MP, Manfredi AA, Mezzapelle R, Rovere Querini P and Venereau E: High-mobility group box 1 protein orchestrates responses to tissue damage via inflammation, innate and adaptive immunity, and tissue repair. Immunol Rev 280: 7482, 2017.

46 Martins I, Wang Y, Michaud M, Ma Y, Sukkurwala AQ, Shen S, Kepp O, Métivier D, Galluzzi L, Perfettini JL, Zitvogel L and Kroemer G: Molecular mechanisms of ATP secretion during immunogenic cell death. Cell Death Differ 21: 79-91, 2014.

47 de Bruyn M, Wiersma VR, Helfrich W, Eggleton P and Bremer E: The ever-expanding immunomodulatory role of calreticulin in cancer immunity. Front Oncol 5: 1-6, 2015.
48 Shimizu K, Yamasaki S, Shinga J, Sato Y, Watanabe T, Ohara O, Kuzushima K, Yagita H, Komuro Y, Asakura M and Fujii SI: Systemic DC activation modulates the tumor microenvironment and shapes the long-lived tumor-specific memory mediated by CD8+T cells. Cancer Res 76: 3756-3766, 2016.

49 Sistigu A, Yamazaki T, Vacchelli E, Chaba K, Enot DP, Adam J, Vitale I, Goubar A, Baracco EE, Remédios C, Fend L, Hannani D, Aymeric L, Ma Y, Niso-Santano M, Kepp O, Schultze JL, Tüting T, Belardelli F, Bracci L, La Sorsa V, Ziccheddu G, Sestili P, Urbani F, Delorenzi M, Lacroix-Triki M, Quidville V, Conforti R, Spano JP, Pusztai L, Poirier-Colame V, Delaloge S, Penault-Llorca F, Ladoire S, Arnould L, Cyrta J, Dessoliers MC, Eggermont A, Bianchi ME, Pittet M, Engblom C, Pfirschke C, Préville X, Uzè G, Schreiber RD, Chow MT, Smyth MJ, Proietti E, André F, Kroemer G and Zitvogel L: Cancer cell-autonomous contribution of type I interferon signaling to the efficacy of chemotherapy. Nat Med 20: 1301-1309, 2014.

50 Gebremeskel S, Clattenburg DR, Slauenwhite D, Johnston B, Gebremeskel S, Clattenburg DR, Slauenwhite D, Gebremeskel S, Clattenburg DR, Slauenwhite D, Lobert L and Johnston B: Natural killer $\mathrm{T}$ cell activation overcomes immunosuppression to enhance clearance of postsurgical breast cancer metastasis in mice. Oncoimmunology 4: e995562, 2015.

51 Tanaka T, Fujita M, Hasegawa H, Arimoto A, Nishi M, Fukuoka E, Sugita Y, Matsuda T, Sumi Y, Suzuki S, Kakeji Y and Yamashita K: Frequency of myeloid-derived suppressor cells in the peripheral blood reflects the status of tumor recurrence. Anticancer Res 37: 3863-3869, 2017.

52 Gebremeskel S, Lobert L, Tanner K, Walker B, Oliphant T, Clarke LE, Dellaire G and Johnston B: Natural killer T-cell immunotherapy in combination with chemotherapy-induced immunogenic cell death targets metastatic breast cancer. Cancer Immunol Res 5: 1086-1097, 2017.

Received April 11, 2018

Revised May 16, 2018

Accepted May 17, 2018 